\title{
CMOS Realization of VDTA Based Electronically Tunable Wave Active Filter with Minimum Power Consumption at Low Supply Voltage $\pm 0.82 \mathrm{~V}$
}

\author{
Ghanshyam Singh \\ Department of Electronics and Communication Engineering, Jayamukhi Institute of Technological Sciences Affiliated to JNTUH, \\ Warangal, India \\ Email: ghanshyamsingh_09@rediffmail.com
}

How to cite this paper: Singh, G. (2020) CMOS Realization of VDTA Based Electronically Tunable Wave Active Filter with Minimum Power Consumption at Low Supply Voltage \pm 0.82 V. Circuits and Systems, 11, 11-26.

https://doi.org/10.4236/cs.2020.112002

Received: January 23, 2020

Accepted: February 25, 2020

Published: February 28, 2020

Copyright $\odot 2020$ by author(s) and Scientific Research Publishing Inc. This work is licensed under the Creative Commons Attribution International License (CC BY 4.0).

http://creativecommons.org/licenses/by/4.0/

\begin{abstract}
This paper presents a higher order voltage and current mode low pass or high pass filter for wave active filter based on Voltage Differencing Transconductance Amplifiers (VDTAs). The wave equivalent variable technique and topological simulation as well as operational realization using wave variables techniques are proposed for basic active building blocks of wave active filters. The proposed wave equivalent technique is employed for wave active filter with the proper selection of the terminal connections. This work presented the basic element for the realizing wave active filter is the series inductor with parallel grounded capacitor. The proposed wave active filter is verified by realizing a 4th order low pass and high pass Butterworth filter with minimum power consumption at $\pm 0.82 \mathrm{~V}$ using SPICE simulation with $0.18 \mu \mathrm{m}$ TSMC CMOS technology parameters.
\end{abstract}

\section{Keywords}

Wave Active Filter, Voltage Differencing Transconductance Amplifier, Voltage/Current Mode, CMOS Technology

\section{Introduction}

The current mode active building blocks approaches for analog signal processing and digital signal processing circuits as compared to voltage mode active building blocks due to its high potential performance such as larger bandwidth, less circuit complexity, large dynamic range, higher operating speed, very low power 
consumption and low operating voltage. The proposed active building block is operate in current mode, voltage mode and mixed mode.

The high order active filters can be simulated by the reflection of the behavior of LC ladder prototype active wave filters. The larger number of design approaches for these filters have been already discussed in the reported literature Universal Current Mode biquad filter using VDTA [1], Universal Current Mode biquad filter using VDTA, Universal Current Mode biquad filter using VDTA [2]. The purpose of the wave equivalent method was to derive wave active filter based on scattering parameters.

The realization of proposed wave active filter is based on the use of wave variables, therefore the scattering matrix will play vital role in the realization of wave active filters, as already discussed active elements reported references.

Single VDVTA Based VM biquad filter [3], Single MO-CCCCTA-based electronically tunable current/Trans-impedance-mode biquad universal filter [4], Electronically tunable low voltage mixed mode universal biquad filter [5], Electronically tunable CCCCTA based cascadable current mode universal biquad filter [6]. Wave active filters using various Active Building Blocks are reported in the literature such as Cascadable low voltage operated current mode biquad filter [7], Current processing current controlled universal biquad filter [8], Digitally controlled fully Differential Voltage and TAM biquad filter, transadmittance type universal current mode biquad filter using VDTA [9], Trans-admittance type universal current-mode biquad filter using VDTAs [10], VDTA based Electronically tunable voltage mode and TAM biquad filter [11], A new transadmittance mode biquad filter using MOVDTA [12], New simple CMOS Realization of voltage differencing transconductance amplifier [13], A low voltage operable (VDTA) based biquad filter realizing BP, HP filter functioning in Transadmittance Mode (TAM) [14], Differential Voltage Controlled Current Conveyor Transconductance Amplifier based wave active filter (DVCCCTA) [15], Current Controlled differential difference Current conveyor Transconductance Amplifier (CCDDCCTA) [16], New simple CMOS Realization of voltage differencing Transconductance Amplifier (VDVTA) [17], A review of the evolution of current mode circuits and techniques and various mode analog building blocks [18], Compact voltage differencing Transconductance Amplifier (VDTA) based current mode electronically tunable universal filter [19], Electronically tunable resistorless mixed mode biquad filter [20], Universal voltage mode Biquad Filter using voltage differencing Transconductance Amplifier (VDVTA) [21]. This paper presents the realization of wave active filter using a recently introduced active building block as VDTA.

The Wave Active Filter equivalent is developed with the use of an inductor in series branch and a capacitor in parallel branch using VDTAs.

The workability and function ability of $4^{\text {th }}$ order low pass Butterworth filter is thus verified through SPICE simulation using $0.18 \mu \mathrm{m}$ TSMC CMOS technology parameters. 


\section{Proposed Wave Equivalent Technique for VDTAs Based Wave Active Filter}

In this section the proposed VDTA has been presented to simulate higher order wave active filter.

There are so many techniques are available in the reported literatures for simulating higher order wave active filters using component replacement technique, Impedance scaling technique and operating simulating techniques. In the reported literature the proposed techniques employ loss less integrator which is not possible to implement integrator circuits with active and passive component imperfections.

Realization of the proposed wave active filter is employed with VDTA using wave equivalent technique.

\section{The Reported Wave Active Filter Is Presented Following Advantageous Features}

1) Simple CMOS realization of VDTA.

2) It uses only active element and grounded capacitor.

3) VDTA based wave active filter yields an advantageous feature of Electronic tunability with different bias current of VDTA.

4) Newly proposed active building block gives a registerless configuration.

5) Realization of wave active filter due to presence of VDTAs based Transconductance Amplifier.

6) Proposed wave equivalent as well as component replacement and operational simulation techniques of LC ladder type filter structure possesses electronic tunability at the simulated and theoretical cut off frequencies.

7) Transconductance of VDTA can be controlled with the help of different bias current.

\section{Description of Newly Introduced Active Building Block VDTA for Proposed Wave Active Filter}

VDTA is newly introduced active building block which has two voltage inputs terminals and two current output terminals.

The symbolical representation of VDTA is shown in Figure 1, which has the

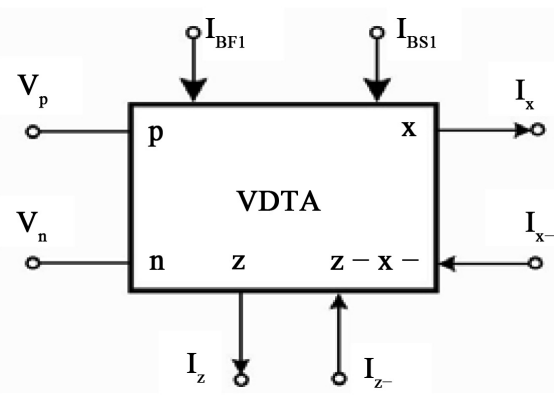

Figure 1. Symbolical representation of VDTA with different bias currents $\left(I_{B}\right): I_{B F 1}=I_{B 1}, I_{B S 1}=I_{B 2}$ etc. 
two voltage input terminals of VDTA are represented as $V_{P}$ and $V_{N}$ and four output terminals are $Z^{+}, Z, X^{+}$and $X^{-}$.

The terminal characteristic equation of the VDTA can be presented in Equation (1).

$$
\left[\begin{array}{l}
I_{Z+} \\
I_{Z-} \\
I_{X+} \\
I_{X-}
\end{array}\right]=\left|\begin{array}{cccc}
g_{m 1} & -g_{m 1} & 0 & 0 \\
-g_{m 1} & g_{m 1} & 0 & 0 \\
0 & 0 & g_{m 2} & 0 \\
0 & 0 & -g_{m 2} & 0
\end{array}\right|\left[\begin{array}{c}
V_{P} \\
V_{N} \\
V_{Z+} \\
V_{z-}
\end{array}\right]
$$

The CMOS realization of VDTA based Wave Active Filter is shown in Figure 2. The design and development of the wave active filter depend on wave equivalent and component replacement techniques.

Wave equivalent technique focus on the modeling of incident waves and reflected waves. The incident waves and reflected waves for the Wave.

Active Filter is characterized by the Equation (2):

$$
A_{j}=V_{j}+I_{j} R_{j} \text { and } B_{j}=V_{j}-I_{j} R_{j}
$$

The wave voltage of the incident waves and reflected waves for the proposed wave active filter is presented in Equation (2) where $j=1,2$.

Whereas $A_{j}$ represent incident waves, $B_{j}$ represent reflected waves, $R_{j}$ represent port normalization resistance of port $j$.

The CMOS realization of the VDTA based Wave Active Filter is shown in Figure 2 with the help of Equation (2) the wave equivalent technique is used for the replacement of the components of wave active filter defined by the scattering matrix in Equation (5).

The basic two port network of wave active filter is shown in the Figure 3. We describe that these voltage $(V)$ and current $(I)$ port variables are related by means of a transmission matrix $[A]$ of two port sub network for proposed wave

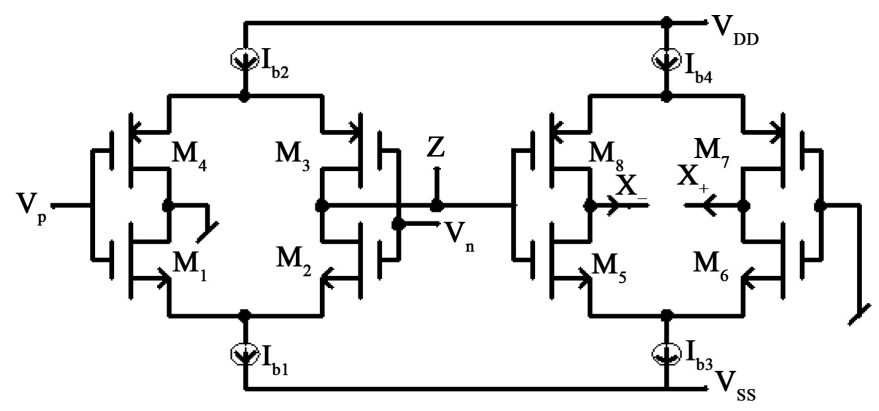

Figure 2. CMOS realization of VDTA for wave active filter with different bias currents $I_{b 1}, I_{b 2}, I_{b 3}, I_{b 4}$.

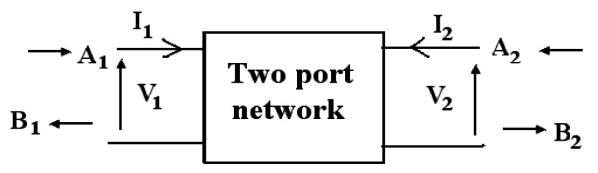

Figure 3. Basic two port network for proposed wave active filter. 
active filter is presented by:

$$
\left[\begin{array}{l}
V_{1} \\
I_{1}
\end{array}\right]=\left|\begin{array}{ll}
a_{11} & a_{12} \\
a_{21} & a_{22}
\end{array}\right|\left[\begin{array}{c}
V_{2} \\
I_{2}
\end{array}\right]
$$

Whereas $[A]=\left|\begin{array}{ll}a_{11} & a_{12} \\ a_{21} & a_{22}\end{array}\right|$

The two port network for Proposed Wave Active Filter is shown in Figure 4(a) and Wave Variables Equivalent for two port sub network of the Proposed wave active filter is shown in Figure 4(b).

The component replacement with wave equivalent is presented in Figure 5.

The wave equivalent technique is used for the replacement of the components of wave active filter. It is defined by the scattering matrix $[S]$.

The two port sub network of wave active filter can be characterized in terms of the scattering parameters $[S]$ with the help of Equation (2) described as:

Similarly $[S]=\left|\begin{array}{ll}S_{11} & S_{12} \\ S_{21} & S_{22}\end{array}\right|,[A]$ and $[S]$ are the transmission matrix of the two port sub network for the wave active filter.

Now we introduce the linear transformation to the two port variables for wave equivalent variables with the help of Equation (2).

$$
\left[\begin{array}{l}
B_{1} \\
B_{2}
\end{array}\right]=[S]\left[\begin{array}{l}
A_{1} \\
A_{2}
\end{array}\right]
$$

The relation between $A_{1}, A_{2}, B_{1}$ and $B_{2}$ for wave equivalent technique and the replacement of the components are reported in Equation (4) for CMOS.

Realization of the VDTA based Wave Active Filter. The scattering matrix of Equation (4) presented as:

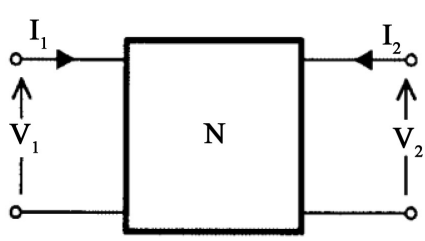

(a)

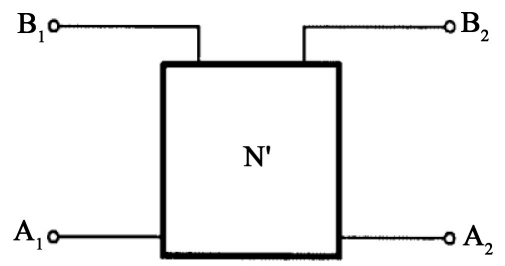

(b)

Figure 4. (a) Basic-two port network and (b) Wave equivalent two port network.

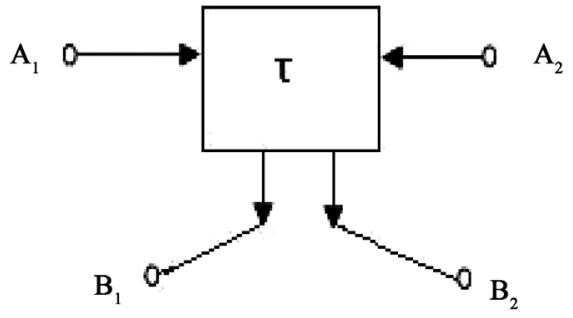

Figure 5. Component replacement with wave equivalent. 


$$
\left[\begin{array}{l}
B_{1} \\
B_{2}
\end{array}\right]=\left|\begin{array}{ll}
S_{11} & S_{12} \\
S_{21} & S_{22}
\end{array}\right|\left[\begin{array}{l}
A_{1} \\
A_{2}
\end{array}\right]
$$

The modified Equation (3) represents the Transmission Matrix of the Proposed Wave Active Filter, which is presented in Equation (6) and Equation (7):

$$
\begin{aligned}
& \left|\begin{array}{ll}
a_{11} & a_{12} \\
a_{21} & a_{22}
\end{array}\right| z=\left|\begin{array}{cc}
1 & -z \\
0 & -1
\end{array}\right| \\
& \left|\begin{array}{ll}
a_{11} & a_{12} \\
a_{21} & a_{22}
\end{array}\right| y=\left|\begin{array}{cc}
1 & 0 \\
y & -1
\end{array}\right|
\end{aligned}
$$

Equations (6) and (7) related with the wave variables equivalent for the Proposed Wave Active Filter design. It is an alternate solution to the simulation of resistively terminated LC ladder type structure.

Each element of the passive ladder is treated as an elementary two port and it's active RC equivalent is determined after its voltage and current variables have been linearly transformed to the wave equivalent variables.

$$
\begin{gathered}
S_{11}=\left(\frac{a_{11}-a_{21} R_{1}-a_{12} G_{2}+a_{22} R_{1} G_{2}}{\Delta}\right) \\
S_{12}=\frac{R_{1} G_{2}}{\Delta} \\
S_{21}=\frac{1}{\Delta} \\
S_{22}=\left(\frac{a_{11}+a_{21} R_{1}+a_{12} G_{2}+a_{22} R_{1} G_{2}}{\Delta}\right) \\
\Delta=a_{11}+a_{21} R_{1}-a_{12} G_{2}-a_{22} R_{1} G_{2} \\
a_{2}=\frac{1}{R_{2}} \\
g_{m 2}=\frac{\left(g_{m 5}+g_{m 8}\right)}{2}=\frac{\left(g_{m 6}+g_{m 7}\right)}{2} \\
g_{m 1}=\frac{\left(g_{m 3}+g_{m 4}\right)}{2} \\
g_{i}=\sqrt{I_{B i} \mu_{i} C_{o x}\left(\frac{W}{L}\right)}
\end{gathered}
$$

where $g_{i}$ is the transconductance of the $\mathrm{i}^{\text {th }}$ MOS Transistors.

The series arm inductor $(L)$ with parallel arm capacitor $(C)$ can be described in terms of scattering

$$
S=\frac{1}{1+s \tau}\left|\begin{array}{cc} 
\pm s \tau & 1 \\
1 & \pm s \tau
\end{array}\right|
$$

The Characteristic Resistance $\left(R_{X}\right)$ of terminated LC ladder type structure is given by:

$$
R_{X}=\sqrt{2 m_{n} C_{o X}\left(\frac{W}{L}\right) I_{B 1}+2 m_{p} C_{o X}\left(\frac{W}{L}\right) I_{B 1}} \text { and }
$$




$$
g_{m}=\sqrt{2 \mu_{n} C_{o x}\left(\frac{W}{L}\right) I_{B 2}}
$$

The implementation of wave Equation (11) for series inductor $(L)$ and parallel capacitor $(C), \tau=\frac{L}{2 R}$ Where $\tau$ is time constant, $R$ is the port resistance and $L$ is the Inductance.

\subsection{Single VDTA Based Lossy Integration Application as a Summer and Subtractor}

$$
B_{1}=A_{1}-\frac{1}{1+s \tau}\left|A_{1}-A_{2}\right|
$$

Similarly

$$
B_{2}=A_{2}-\frac{1}{1+s \tau}\left|A_{1}-A_{2}\right|
$$

The wave Equation (12) and Equation (13) are described for summation and subtraction of Lossy integration uses a single VDTA.

\subsection{Single VDTA Based Lossy Integration}

Lossy integration uses a single VDTA and one grounded capacitor. Lossy Integrator is shown in the Figure 7. The output voltage $\left(V_{o}\right)$ of the lossy integrator is given by:

$$
V_{o}=\frac{1}{1+s \tau}\left(V_{i n 1}-V_{i n 2}\right)
$$

where as time constant $(\tau)=R_{X} C_{d}$ which does satisfy the condition.

$$
g_{m} R_{X}=1 \text {. }
$$

Now using Equation (12) and Equation (13) then $R_{X} C_{d}=\frac{L}{2 R}$ Assume Port resistance $\left(R_{X}=R\right)$ then the value of Capacitor $\left(C_{d}\right)=\frac{2 L}{R^{2}}$.

\subsection{Single VDTA Based Subtraction Operation for Wave Active Filter}

To implement subtraction operation employing single VDTA then the output of subtraction is given by:

$V_{o}=\left(V_{i n 1}-V_{\text {in } 2}\right)$. The output of subtraction depends on the proper selection of the input voltage and bias current. The subtraction operation satisfies the wave conditions $g_{m 1} R_{1}=1$ and also satisfies the wave condition $g_{m 2} R_{2}=1$.

\subsection{Two VDTAs Based Summer or Adder Operation for Wave Active Filter}

To implement the summer or adder operation employing two VDTAs then the output of summer is given by: $V_{o}=\left(V_{i n 1}+V_{\text {in } 2}\right)$. The output of summer depends on the proper selection of the input voltage and bias current. The subtraction 
operation satisfies the wave conditions $g_{m 1} R_{1}=1$ and also satisfies the wave condition $g_{2} R_{2}=1$.

\subsection{Wave Equivalent and Operational Simulation Techniques for LC Ladder Type Structure}

The topological and simulation operation of basic proto type LC ladder type structure shown in Figure 6(a).

Filter with admittance in series arm and impedance in shunt arm.

Simulation techniques LC ladder type using newly reported active building block VDTA with series branch admittances $\mathrm{Y}_{2}, \mathrm{Y}_{4}, \mathrm{Y}_{6}$ and parallel branch Impedances $Z_{1}, Z_{3}, Z_{5}$ is reported in Figure 6(b).

\subsection{Complete Structure of VDTA Based Wave Active Filter}

VDTA Based Wave Active Filter consist lossy integrator operation as subtractor and summation operation. Lossy integrator is shown in Figure 7 and complete structure of VDTA based wave active filter is shown in the Figure 8.

\section{CMOS Simulation Results}

The functionability and workability of VDTA based wave active filter application as $4^{\text {th }}$ order low pass and high pass filter are verified through SPICE Simulation with TSMC CMOS Technology $0.18 \mu \mathrm{m}$ parameters. The port relationship of VDTAs based wave active filter has been observed using TSMC $0.18 \mu \mathrm{m}$ technology parameters. The simulated frequency response of VDTA based wave

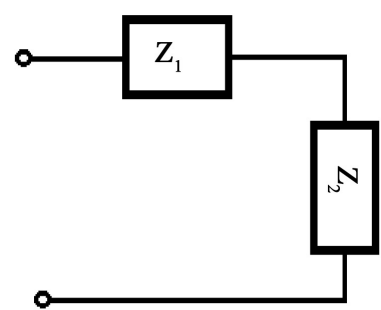

ckt. a

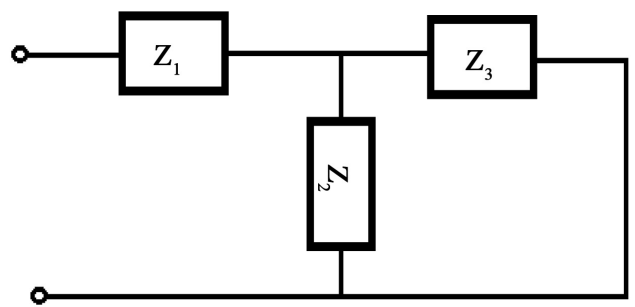

ckt. b

(a)

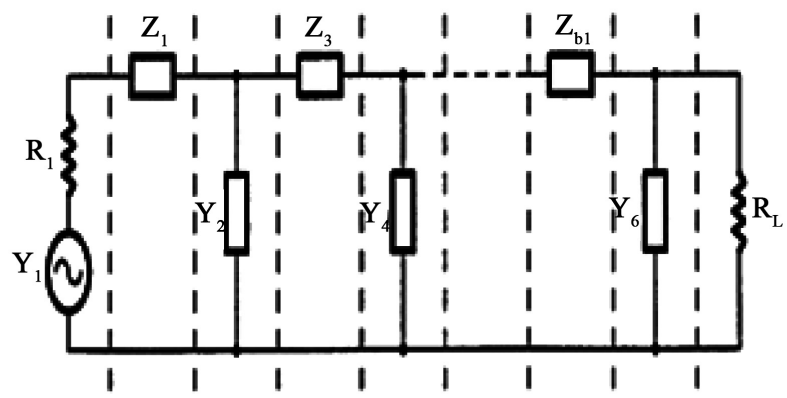

(b)

Figure 6. (a) The basic proto type LC ladder type structure for proposed wave active; (b) The ideal ladder structure of the proposed wave active filter with admittance in series arm and impedance in shunt arm. 


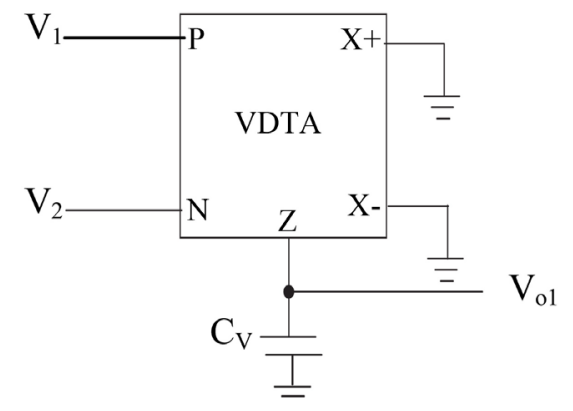

Figure 7. Lossy integrator using VDTA.

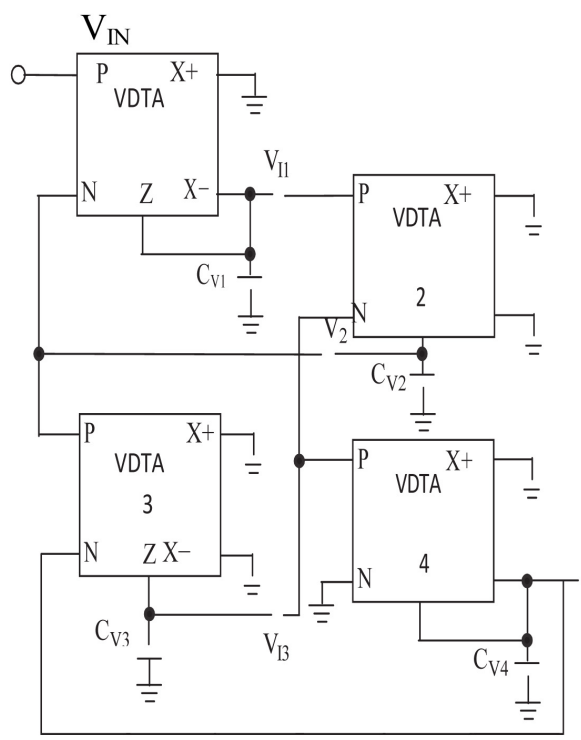

Figure 8. Complete structure of VDTA based wave active filter with lossy integrator operation as subtractor and summation.

active filter application as $4^{\text {th }}$ order low pass and high pass Butterworth filter to observe maximally flat responses are shown in the Figure 10 and Figure 11. The electronic tunability and transconductance variation of the proposed VDTA based wave active filter at different bias current are shown in the Figure 9 and Figure 12. The simulated transient response of input and output for the VDTA based wave active filter is shown in Figure 13. The actual values of $L \& C$ for the wave equivalent can presented in Table 1 and The aspect ratio of the various MOS Transistors for VDTAs is given in Table 2 . The supply voltages are VDD = $-\mathrm{VSS}=0.82 \mathrm{~V}, I_{B}=5 \mu \mathrm{A}, 10 \mu \mathrm{A}, 20 \mu \mathrm{A}, 30 \mu \mathrm{A}, 40 \mu \mathrm{A}, 50 \mu \mathrm{A}, I_{B 1}=8 I_{B 2}$. The transconductance of VDTAs can be controlled with the help of different bias currents are $I_{B 1}=I_{B 2}=I_{B 3}=I_{B 4}=489.13 \mu \mathrm{A}$.

Therefore the transconductances are to be observed

$g_{m 1}=g_{m 2}=g_{m 3}=g_{m 4}=1 \mathrm{~mA} / \mathrm{V}$.

The validation and verification of the proposed VDTAs Based Wave.

Active Filter is defined in the section II and III a higher order or $4^{\text {th }}$ order Low Pass Filter and high pass Butterworth filter. The components values of proto 


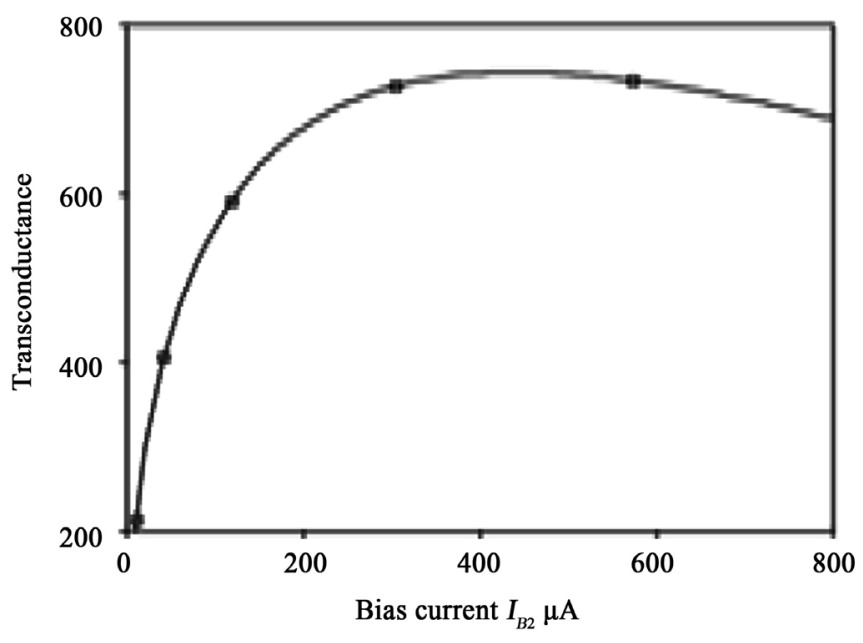

Figure 9. Transconductance variation for different bias current $(\mu \mathrm{A})$.

type and ideal LC ladder filter structure are used $R_{s}=R_{L}=1 \mathrm{k} \Omega, L_{1}=0.2872$ $\mathrm{mH}, L_{2}=0.5744 \mathrm{mH}, C_{1}=0.5744 \mu \mathrm{f}, C_{2}=0.2872 \mu \mathrm{f}$. The VDTAs based wave active filter is implemented using wave equivalents with series inductor $(L)$ and parallel capacitor $(C)$. The theoretical cut off and simulated cut off frequencies are measured by the higher order or $4^{\text {th }}$ order Low Pass Filter and high pass Butterworth filter. The resistor $R_{1}$ and $R_{2}$ are to be selected $1 \mathrm{k} \Omega$ according $g_{m 1} R_{1}=g_{m 2} R_{2}=1$.

The value of capacitor $\left(C_{d}\right)$ for wave equivalent of series inductors $\left(L_{1}=\right.$ $\left.0.1432 \mathrm{mH}, L_{2}=0.2864 \mathrm{mH}\right) C_{1}=0.2864 \mu \mathrm{f}, C_{2}=0.1432 \mu \mathrm{f}$.

Simulated Frequency response observed maximally flat response of $4^{\text {th }}$ order Low Pass Filter and high pass Butterworth filter are shown in Figure 10 and Figure 11 by using typical values of components for proto type and ideal LC ladder filter structure are used $R_{s}=R_{L}=1 \mathrm{k} \Omega, L_{1}=1 \mathrm{mH}, L_{2}=2 \mathrm{mH}, C_{1}=2 \mu f$, $C_{2}=1 \mu \mathrm{f}$.

Therefore all the simulated parameters of the proposed VDTAs based wave active filter are shown in Table 3. Application as 4th order Low Pass Filter and high pass Butterworth filters are fully electronically tunable with different bias currents is compared with the previous reported voltage mode configuration is shown in Table 4.

The electronic tunability and transient response are shown in Figure 12 and Figure 13. The total harmonic distortion for the input signal $(\mathrm{mV})$ at maximum output noise voltage is shown in Figure 14. The theoretical cut off and simulated cut off frequencies are shown in the Figure 15. The wave equivalent of the $4^{\text {th }}$ order low pass filter is shown in Figure 16.

\section{Performance Evaluation}

The performance of the proposed VDTAs based wave active filter configuration is presented as application $4^{\text {th }}$ order low pass and high pass filter at $\pm 0.82 \mathrm{~V}$ in 


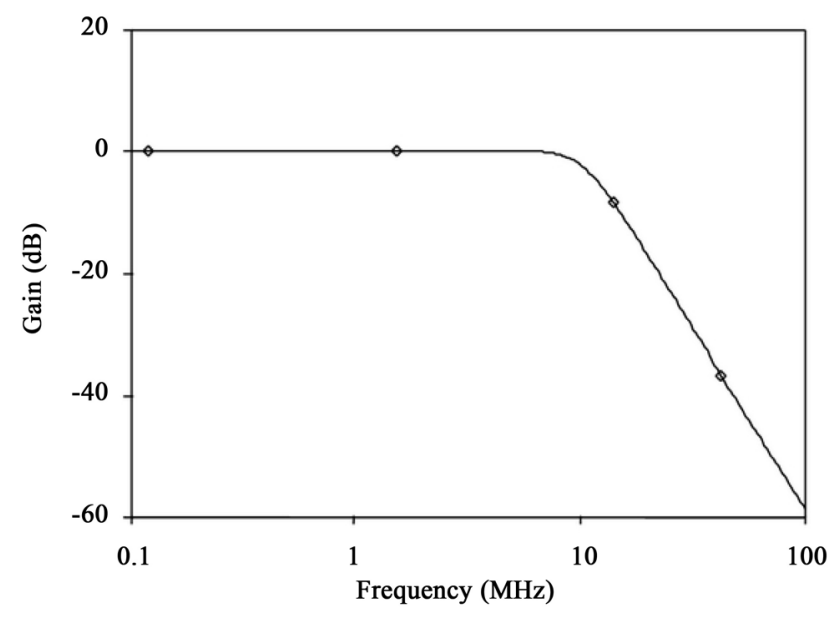

Figure 10. Frequency response of $4^{\text {th }}$ order low pass filter.

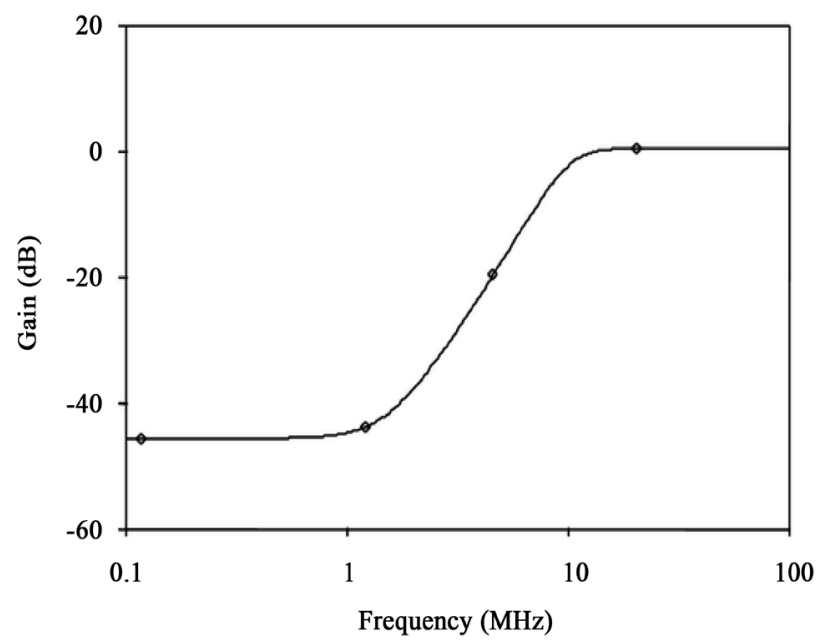

Figure 11. Frequency response of $4^{\text {th }}$ order high pass filter.
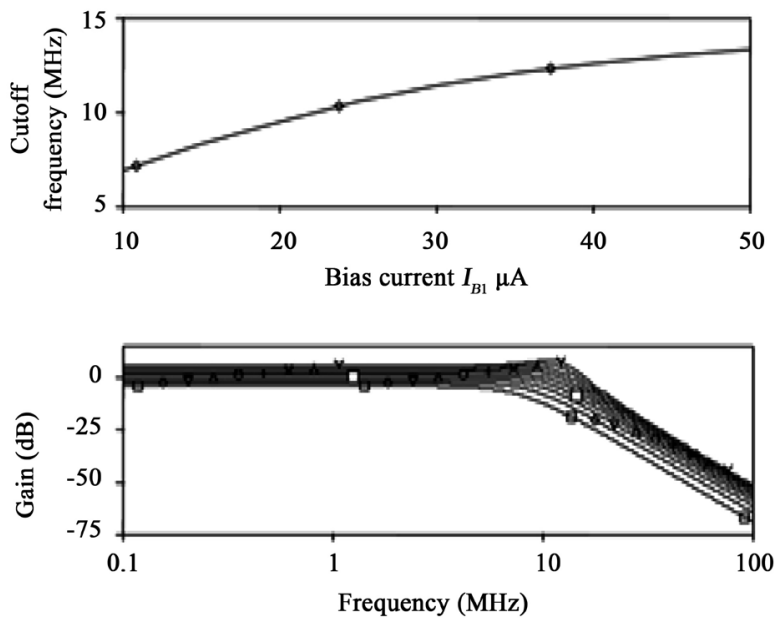

Figure 12. Simulation result shows electronic tunability representation as: 1) Cut off frequency variation with different bias current. 2) Frequency response for different bias current. 

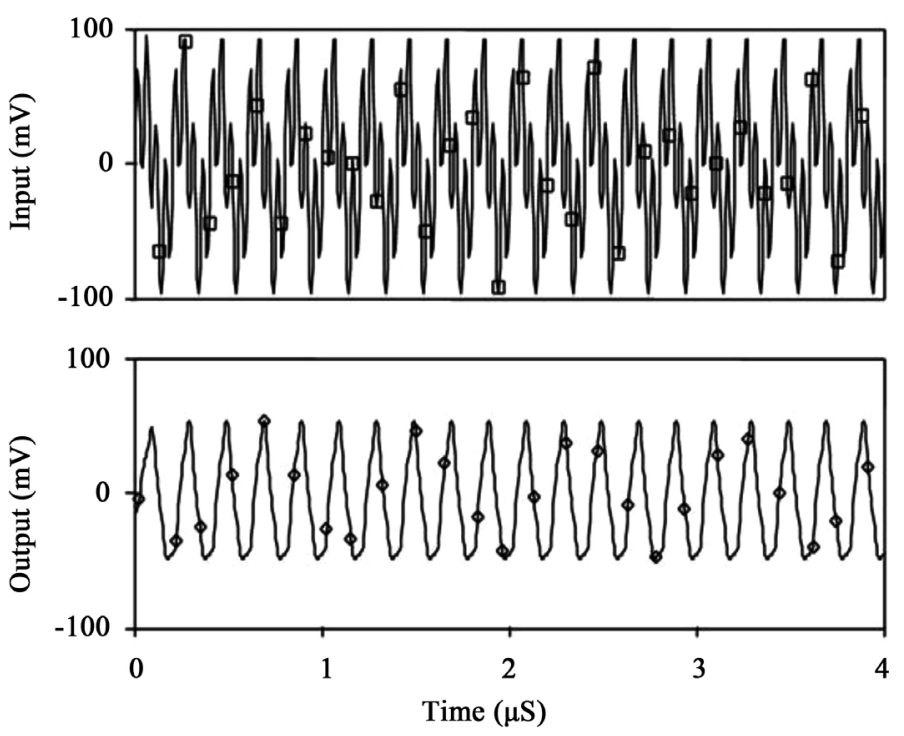

Figure 13. Transient response of input and output signal.

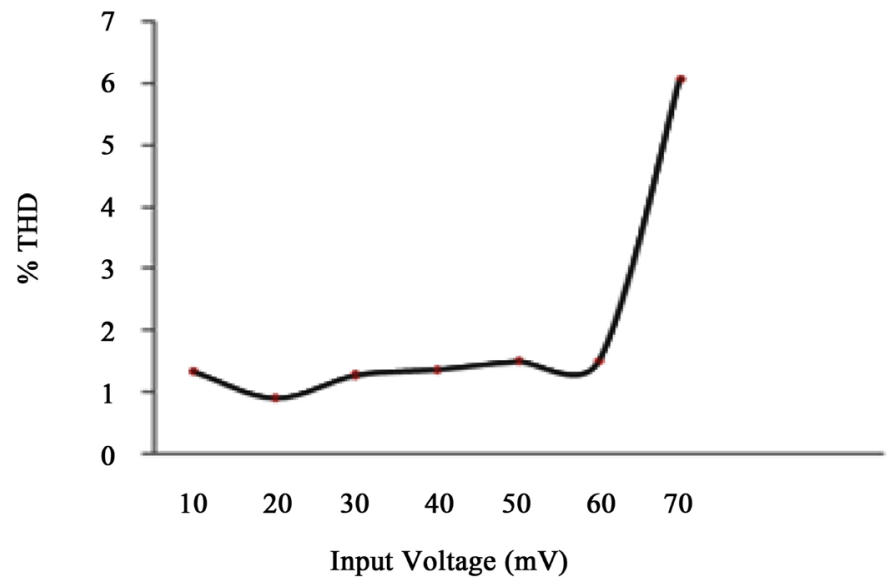

Figure 14. Total harmonic distortion.

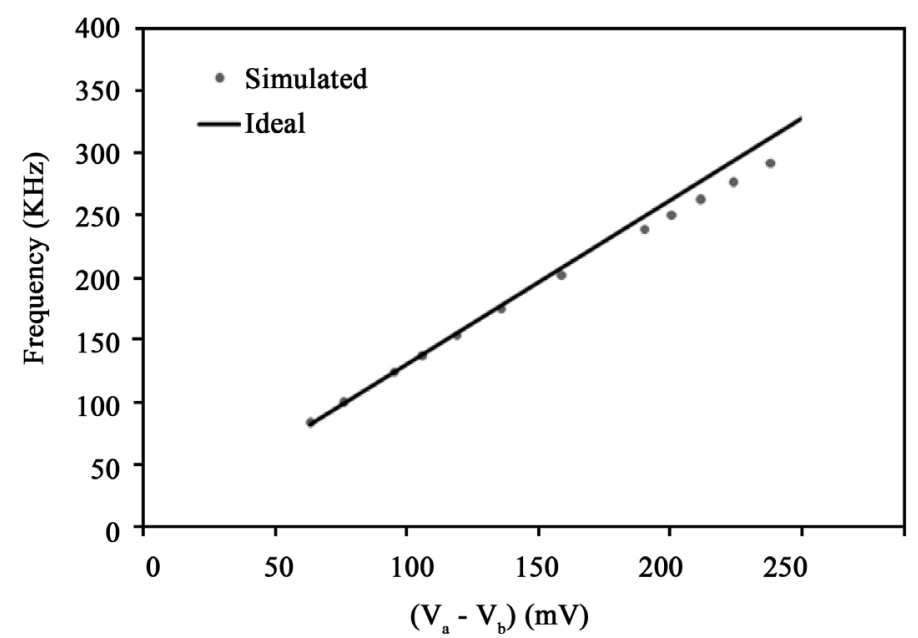

Figure 15. Comparison between theoretical cut off frequency and simulated cut off frequency. 


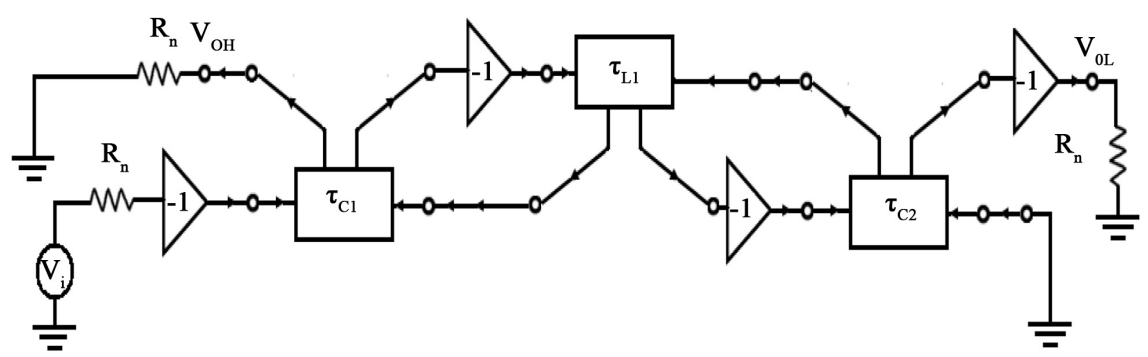

Figure 16. Wave equivalent of circuit of LPF for wave active filter.

Table 1. Wave equivalent techniques for elementary two ports consisting single VDTA in series Inductor and parallel capacitor.

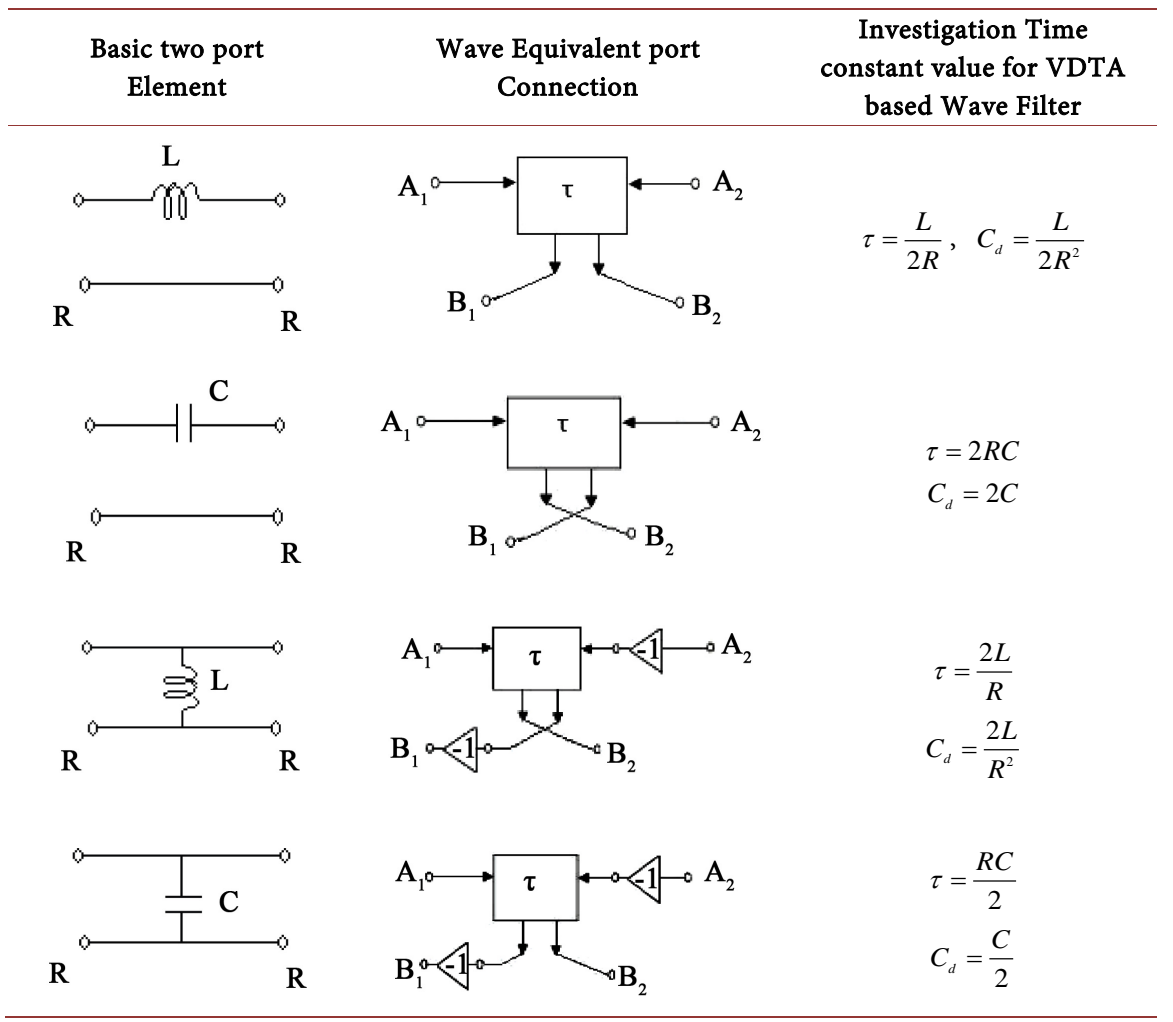

Table 2. MOS transistor aspect ratio.

\begin{tabular}{cccc}
\hline S. No. & MOS Transistors & $W(\mu \mathrm{m})$ & $L(\mu \mathrm{m})$ \\
\hline 1. & $\mathrm{M}_{1}, \mathrm{M}_{2}, \mathrm{M}_{3}, \mathrm{M}_{4}$ & 4.0 & 0.35 \\
2. & $\mathrm{M}_{5}, \mathrm{M}_{6}, \mathrm{M}_{7}, \mathrm{M}_{8}$ & 12.25 & 0.35 \\
\hline
\end{tabular}

terms of frequency response, low power consumption, output noise voltage, transient response of input and output, \% THD. Maximum output noise voltage is better in VDTAs based wave active filter.

\section{Conclusions}

In this paper, VDTAs based wave active filter is presented. The proposed configuration employ lossy integrator as subtractor and summation block and suitable 
Table 3. Simulated parameters of VDTAs based wave active filter.

\begin{tabular}{cll}
\hline S. No. & \multicolumn{1}{c}{ Simulated Parameters } & \multicolumn{1}{c}{ Simulated Results } \\
\hline 1. & $\begin{array}{l}\text { Theoretical Cut off Frequency } \\
\text { Simulated cut off frequency }\end{array}$ & $\begin{array}{l}\text { 348.678 KHz } \\
\text { 249.89 KHZ }\end{array}$ \\
2. & Transconductance value of VDTA & $597.89 \mu \mathrm{S}$ at $360 \mu \mathrm{A}$ \\
3. & Bias Current & $10 \mu \mathrm{A}-50 \mu \mathrm{A}$ \\
4. & Power Consumption & $262.3 \mathrm{~mW}$ \\
5. & Total output Noise Voltage & $1.54-3.86 \mathrm{~V} / \mathrm{HZ}^{1 / 2}$ \\
6. & \% Total Harmonic Distortion & $1.68-6.67$ for $100 \mathrm{mV}$ peak to peak input \\
7. & Operating Voltage, VDD $=-\mathrm{VSS}$ & $0.82 \mathrm{~V}$ \\
\hline
\end{tabular}

Table 4. Comparative study VDTA based wave active with voltage mode filter structure.

\begin{tabular}{|c|c|c|c|c|c|c|}
\hline Ref & $\begin{array}{c}\text { Filter } \\
\text { structure }\end{array}$ & $\begin{array}{l}\text { Active Building } \\
\text { Block and } \\
\text { Technology }\end{array}$ & $\begin{array}{c}\text { Power } \\
\text { Consumption }\end{array}$ & $\%$ THD & $\begin{array}{c}\text { Output } \\
\text { Noise } \\
\text { Voltage }\end{array}$ & $\begin{array}{l}\text { Electronic } \\
\text { tunability }\end{array}$ \\
\hline [4] & $\begin{array}{l}\text { LP, HP, BP, } \\
\text { BR, AP }\end{array}$ & $\begin{array}{l}\text { MO CCCCTA } \\
\text { CMOS Technology } \\
0.35 \mu \mathrm{m}\end{array}$ & $0.629 \mathrm{~mW}$ & $<4 \%$ & 2.5 & Yes \\
\hline [14] & $\begin{array}{l}\text { LP, BP, HP, } \\
\text { BR, AP }\end{array}$ & $\begin{array}{l}\text { VDTA PSPICE in } \\
0.35 \mu \mathrm{m} \text { CMOS } \\
\text { Technology }\end{array}$ & $992 \mathrm{~mW}$ & $2.62-4.33$ & NA & Yes \\
\hline [15] & $\begin{array}{l}3^{\text {rd }} \text { order } \\
\text { Butter worth } \\
\text { LPF }\end{array}$ & $\begin{array}{l}\text { DVCCCTA CMOS } \\
\text { Technology } 0.25 \mu \mathrm{m} \text {, } \\
\text { power supply } \\
\pm 1.25 \mathrm{~V}\end{array}$ & $59.2 \mathrm{~mW}$ & $\begin{array}{l}<5 \% \text { at } \\
225 \mathrm{mV}\end{array}$ & NA & Yes \\
\hline $\begin{array}{c}\text { Proposed } \\
\text { work }\end{array}$ & $\begin{array}{l}4^{\text {th }} \text { order } \\
\text { Butter worth } \\
\text { LPF, HPF }\end{array}$ & $\begin{array}{l}\text { VDTACMOS } \\
\text { Technology } 0.18 \mu \mathrm{m} \text {, } \\
\text { power supply } \\
\pm 0.82 \mathrm{~V}\end{array}$ & $268.3 \mathrm{~mW}$ & $1.68-4.56$ & 1.54 & Yes \\
\hline
\end{tabular}

for integration the simulation results are included to present the workability and functionability of the VDTAs based wave active filter.

The proposed configuration offers following advantageous features:

1) The proposed VDTAs based wave active filter is limited for realizing $4^{\text {th }}$ order low pass and high pass filter responses at $0.82 \mathrm{~V}$.

2) It shows very low active and passive sensitivities.

3) This configuration presents low power configuration.

4) The proposed configuration is more suitable in monolithic integrated circuits for used in analog signal processing, microelectronics system such as instrumentation and control system and wireless communication, voice and data communication.

5) In future, the proposed VDTAs based wave active filter can be widely used in audio and biomedical applications at low power supply voltage. 


\section{Conflicts of Interest}

The author declares no conflicts of interest regarding the publication of this paper.

\section{References}

[1] Prasad, D., Bhaskar, D.R. and Srivatava, M. (2013) Universal Current-Mode Biquad Filter Using a VDTA. Circuits and Systems, 4, 29-33. https://doi.org/10.4236/cs.2013.41006

[2] Prasad, D., Bhaskar, D.R. and Srivatava, M. (2013) Universal Voltage-Mode Biquad Filter Using VDTA. Indian Journal of Pure and Applied Physics, 51, 864-868.

[3] Singh, G., Prasad, D. and Bhaskar, D.R. (2015) Single VDVTA Based Voltage-Mode Biquad Filter. Circuit and System, 6, 55-59. https://doi.org/10.4236/cs.2015.63006

[4] Singh, S.V., Maheshwari, S. and Chauhan, D.S. (2011) Single MO-CCCCTA-Based Electronically Tunable Current/Trans-Impedance-Mode Biquad Universal Filter. Circuit and System, 2, 1-6. https://doi.org/10.4236/cs.2011.21001

[5] Maheshwari, S., Singh, S.V. and Chauhan, D.S. (2011) Electronically Tunable Low Voltage Mixed-Mode Universal Biquad Filter. IET Circuits, Devices and Systems, 5, 149-158. https://doi.org/10.1049/iet-cds.2010.0061

[6] Singh, S.V., Maheshwari, S. and Chauhan, D.S. (2014) Electronically Tunable CCCCTABased Cascadable Current-Mode Universal Biquad Filter. Journal of Active and Passive Electronic Devices, 9, 39-51.

[7] Tomar, R.S., Singh, S.V. and Chauhan, D.S. (2014) Cascadable Low Voltage Operated Current-Mode Universal Biquad Filter. WSEAS Transactions on Signal Processing, 10, 345-353.

[8] Singh, S.V., Maheshwari, S. and Chauhan, D.S. (2012) Current Processing Current Controlled Universal Biquad Filter. Radioengineering, 21, 317-323.

[9] Beg, P., Maheshwari, S. and Siddiqi, M. (2013) Digitally Controlled Fully Differential Voltage- and Trans-Admittance-Mode Biquadratic Filter. IET Circuits, Devices and Systems, 7, 193-203. https://doi.org/10.1049/iet-cds.2012.0244

[10] Prasad, D., Srivastava, M. and Bhaskar, D.R. (2014) Trans-Admittance Type Universal Current-Mode Biquad Filter Using VDTAs. International Scholary Research Notice, 2014, Article ID: 762845. https://doi.org/10.1155/2014/762845

[11] Gupta, G., Singh, S.V. and Bhooshan, S.V. (2015) VDTA Based Electronically Tunable Voltage-Mode and Trans-Admittance Biquad Filter. Circuits and Systems, 6, 93-102. https://doi.org/10.4236/cs.2015.63010

[12] Shankar, C. and Singh, S.V. (2015) A New Trans-Admittance Mode Biquad Filter Using MO-VDTA. WSEAS Transaction on Circuits and Systems, 14, 8-18.

[13] Yesil, A., Kacar, F. and Kuntman, H. (2011) New Simple CMOS Realization of Voltage Differencing Trans-Conductance Amplifier and Its RF Filter Application. Radioengineering, 20, 632-637.

[14] Shankar, C. and Singh, S.V. (2015) A Low Voltage Operable VDTA Based Biquad Filter Realizing Band Pass and High Pass Filtering Functions in TransadmittanceMode. ICCCA-2015, Noida, 15-16 May 2015, 1288-1293. https://doi.org/10.1109/CCAA.2015.7148574

[15] Pandey, N. and Kumar, P. (2011) Differential Voltage Current Conveyer Transconductance Amplifier Based Wave Active Filter. Journal of Electronic Devices, 10, 429-432. 
[16] Pandey, N., Kumar, P. and Choudhary, J. (2013) Current Controlled Differential Difference Current Conveyor Transconductance Amplifier and Its Applications. ISRN Electronics, 2013, Article ID: 968749. https://doi.org/10.1155/2013/968749

[17] Yesil, A., Kacar, F. and Kuntman, H. (2011) New Simple CMOS Realization of Voltage Differencing Transconductance Amplifier and Its RF Filter Application. Radioengineering, 20, 632-637.

[18] Abdalla, K.K., Bhaskar, D.R. and Senani, R. (2012) A Review of the Evolution of Current-Mode Circuits and Techniques and Various Modern Analog Circuit Building Blocks. Nature and Science, 10, 1-13.

[19] Satansup, J. and Tangsrirat, W. (2014) Compact VDTA-Based Current-Mode Electronically Tunable Universal Filters Using Grounded Capacitors. Microelectronics Journal, 45, 613-618. https://doi.org/10.1016/j.mejo.2014.04.008

[20] Yeşil, A. and Kaçar, F. (2013) Electronically Tunable Resistorless Mixed Mode Biquad Filters. Radioengineering, 22, 1016-1025.

[21] Prasad, D., Bhaskar, D.R. and Srivastava, M. (2013) Universal Voltage-Mode Biquad Filter Using Voltage Differencing Transconductance Amplifier. Indian Journal of Pure and Applied Physics, 51, 864-868. 